\title{
From Advantage Perspective Exploring Collaborative Development Between Smart Classrooms and Traditional Classrooms
}

\author{
Xinguo Yu, Weina Cheng* \\ National Engineering Research Center for E-Learning, Central China Normal University, Wuhan, China \\ Email address: \\ 2429346468@qq.com (Xinguo Yu),wncheng@mails.ccnu.edu.cn (Weina Cheng) \\ ${ }^{*}$ Corresponding author
}

\section{To cite this article:}

Xinguo Yu, Weina Cheng. From Advantage Perspective Exploring Collaborative Development Between Smart Classrooms and Traditional Classrooms. Science Innovation. Vol. 7, No. 1, 2019, pp. 1-6. doi: 10.11648/j.si.20190701.11

Received: January 14, 2019; Accepted: February 27, 2019; Published: March 8, 2019

\begin{abstract}
The rise of the future classroom is accompanied by many obstacles, including limited funds, technical and theoretical immaturity. In order to better carry out the construction of educational informatization, this paper uses big data analysis methods to rank the importance of each link and equipment in teaching activities, namely the perspective advantages. Then we propose a new model, which focuses on the advantage perspective input and construction, trying to construct the cooperative development of future classrooms and traditional classrooms on the basis of existing classrooms and maximizes the role of the perspective of superiority, so as to improve the quality of teaching, and discusses this new model in this paper. The feasibility and necessity of the idea.
\end{abstract}

Keywords: Intelligent Classroom, Traditional Classroom, Teaching Design, Advantage Perspective, Cooperative Development

\section{关注优势视角探索未来教室和发展新模式}

余新国, 程维纳*

华中师范大学国家数字化学习工程技术研究中心, 武汉, 中国

\section{邮箱}

2429346468@qq.com（余新国）, wncheng@mails.ccnu.edu.cn（程维纳）

\begin{abstract}
摘要：未来教室的兴起伴随着诸多的阻碍，包括资金有限、技术以及理论不成熟等等。为了更好地开展教育信息化建 设, 本文使用大数据分析手段对教学活动中各个环节和设备进行重要性打分排名, 找出优势视角。并在此基础之上提 出了着重关注优势视角的投入和建设、力图在现有的课堂基础上、最大程度发挥优势视角的作用, 构建未来教室与传 统课堂的协同发展的这一新模式, 提高教学质量, 并且在本文论述了该构想的可行性和必要性。
\end{abstract}

关键词：智慧教室, 传统课堂, 协同发展, 优势视角, 大数据分析 


\section{1. 引言}

近年来, 随着物联网技术和各种移动应用设备的快速 发展, 各种智能终端也越来越普及。人们逐渐习惯了从移 动设备获取知识, 而不再是展现形式更加单纯和枯燥的书 本。

教育领域一直是社会大众和专家学者关注的重点, 新 型的教学设备和教学理念将“未来教室”、“智慧课堂”等关 键字也逐渐送入大众的视野。
统计调查显示, 国内有关未来教室、智慧课堂的研究 最早从1994年开始, 但受经济、科技等因素限制, 最开始 并未受到广泛关注; 直到2008年, 中国开始豁免全国义务 教育阶段的学生[1-2], 教育产业得到进一步发展。2010 年, 国务院常务会议审议并通过《国家中长期教育改革和 发展规划纲要(2010-2020年)》(简称“规划纲要”), 这是中 国进入 21 世纪之后的第一个教育规划, 为全国教育改革和 发展指明了方向，打下了坚实的地基。直到2014开始，“未 来教室”和“智慧课堂”的相关研究进入爆发式增加阶段, 相关论文发表数量的增长速度达到巅峰。

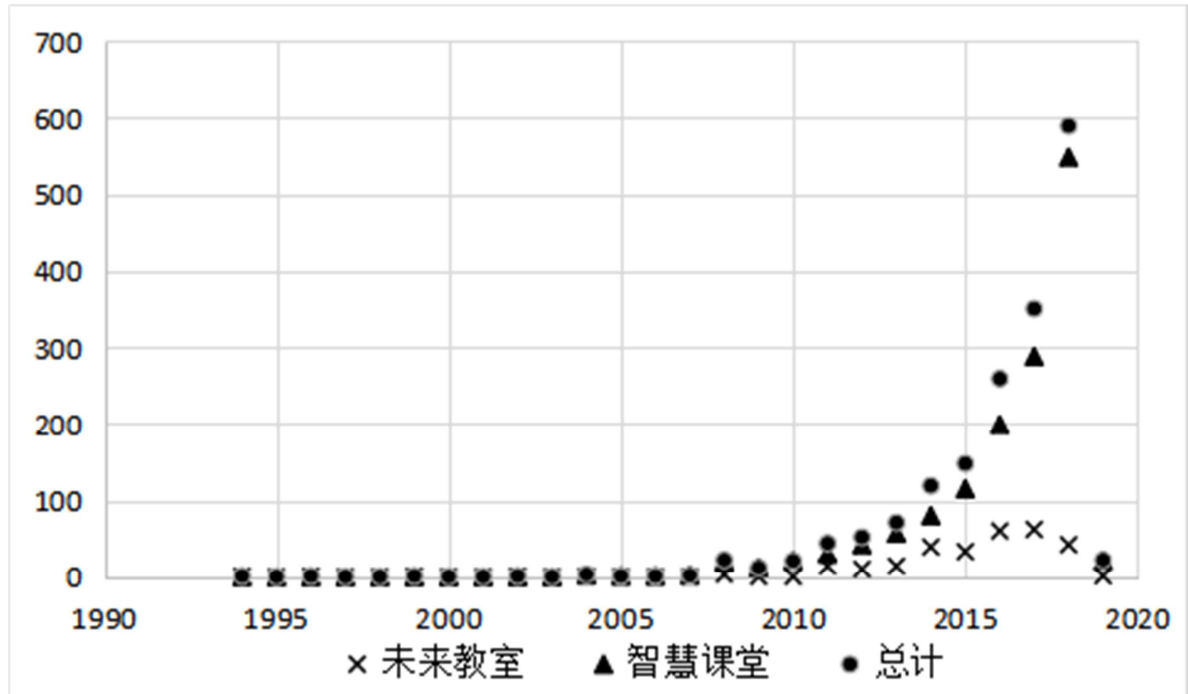

图1 中国知网相关关键字调查报告。

但是调查发现, 国内有关未来教室和传统教室的相关 文献比较少, 以这两者为检索关键字, 在中国知网上检索, 年限范围不限, 结果显示只有四篇文章 [3-6]曾探讨过该问 题, 在相关研究中实在是不起眼。

无可否认的是, 传统课堂确实存在着诸多弊端, 智慧 课堂的兴起已成为必然。但是, 智慧教室的推广并不意味 着传统课堂被完全取代。我国关于未来教室的研究起步较 晚, 目前仍旧存在诸多问题: 理论体系的研究还不成熟, 研究方法比较单一; 相关硬件设备设备造价高、难以普及; 相关知识普及程度不高、众多师生们难以适应新技术、新 环境, 导致资源浪费程度高等问题[7]。依据我国教育领域 的发展现状, 传统课堂的依旧起着至关重要的作用, 无法 断言二十年甚至更远的未来中国课堂会发生怎么样的变 化, 但是当下, 我们更为关心的是在智慧课堂如火如茶的 时候, 传统课堂和智慧课堂如何结合起来发挥作用。

本文结合大数据分析手段, 从教学资源优化、教学模 式创新、硬件投入及建设等方面来探讨, 传统课堂和智慧 课堂未来如何协同发展。

\section{2. 大数据手段寻找优化视角}

大数据在教育行业的应用范围越来越广, 为了优化教 学资源投入, 本文对教学活动中的各个环节和所用到的各 种设备进行了统计, 使用神经网络对所有设备进行排名打
分来判断该设备的重要程度（因为没有相关方面的资料, 笔者假定在众多文献中出现次数、与其他设备相关程度高 即视为更加重要）, 统计结果如下:

表1 影响教学质量的重要因素前五名调查。

\begin{tabular}{lll}
\hline \multirow{2}{*}{ 重要性排名 } & \multicolumn{2}{l}{ 影响教学质量的重要因素 } \\
\cline { 2 - 3 } & 教学环节 & 教学设备 \\
\hline 1 & 课上老师讲解 & 学习资源 \\
2 & 学生课前预习 & 视觉效果呈现设备 \\
3 & 课后复习 & 听觉效果呈现设备 \\
4 & 教学效果自测 & 照明、桌椅等基础设施 \\
5 & 课上交流 & 其他 \\
\hline
\end{tabular}

调查发现, 影响教学质量的重要教学环节集中在课上 老师讲解、学生课前预习、课后复习、教学效果自测、课 上交流。

而教学设备重要性调查结果显示, 室温监测、空调等 设施对教学质量影响较小; 而跟教学活动息息相关的设备, 比如: 教学资源、课上内容效果呈现、灯光照明等对教学 活动影响较大。

\section{3. 传统课堂的优劣势分析}

着名学者袁振国在他的着作“课堂的革命”中对当前 的课堂作了深刻的阐述[8]: 传统课堂造就了传统的师生 关系。在教学中, 教师是主动, 主导者, 学生是被动的, 
顺从的。教师, 学生和家长在社会中一直有潜意识: 学 生应该跟随老师, 听话的学生是好学生; 不能管住学生 的老师不是好教师。知道不能在同等水平上探索科学知识, 教师和学生不能在同等水平上交换意见。

这段话从本质上概括总结了目前传统课堂的最大特 点是: 教师为主学生为辅的教学模式。

\section{1. 传统课堂的弊端}

这种教学模式的弊端是非常明显的:

1. 课堂主体错误。这种教学模式往往形成一种教师单 向灌输为主, 学生被动接受的局面。学生, 作为认知主体, 在整个教学过程中从始至终处于被动地接受知识的地位, 学习的主动性被忽视甚至压抑。

2.知识来源不足。由于观念的局限性, 传统课堂所讲 述的知识大致只局限于课本, 教材甚至已经是十年前甚至 更早的版本, 完全无法跟上信息更新的速度。学生们通常 会发现, 等自己毕业了, 很多的知识都已经“过期”了。传 统课堂学习资源来源途径单一, 目前国内学生在传统课堂 所学到的知识往往来源于书本教材。要知道, 信息时代, 书本的更新速度早已无法跟上信息的更新速度, 如果没有 其他学习资源的汇入, 学生在学习的时候其实已经慢了社 会一步甚至许多步。

3. 教学过程相对枯燥而且形式单一, 无法带动学生 去发挥本身的主动性和积极性。传统课堂是教师施展的 舞台, 学生获得知识的途径主要是通过教师讲解, 学生 在课堂上参与度极低, 这就很容易造成精力流失, 俗称 开小差。

4.忽略了学生的个体性。传统模式很大程度上可以将 老师所掌握的只是系统地、全面的讲解给在座的所有学生。 但是这种教育模式一直忽略了一个问题: 每个学生都是独 立的个体, 他们对不同知识的兴趣、接受度、以及所能接 受的课程进度都是不同的。传统课堂“一刀切”的培养方案 和教学方法, 使得人才培养在着重关注创新和个性化的 21 世纪仍然陷于“批量式”培养的琶处。

5. 教学程式上, 传统课堂重学轻用。传统课堂强调学 习系统的书本知识, 按照教案完成规定的教学任务, 反而 不重视知识的运用, 往往会培养出来所谓的“高分低能”。

\section{2. 传统课堂优势分析}

尽管存在着诸多弊端, 传统课堂依然有许多值得学习 和借鉴的地方。

传统课堂可以最大程度的节约学习资源, 尤其是对于 信息比较落后、经济欠发达的地区。一个传统的课堂对设 备的要求很低, 在我国比较贫苦的山区, 往往一间可以遮 风挡雨的房子、一块可以写字的板子、几根粉笔就可以帮 助大量的孩子们进行启蒙。

而且, 尊师重道一直以来是我国的优良传统, 师生之 间的交流是任何高科技都替代不了的。所以在大胆的进行 课堂的改革和创新时, 笔者并不主张完全摒弃传统, 而是 要在传统课堂和智慧教室之间做一个有机结合, 更大程度 的发挥课堂教书育人的作用。

\section{4. 现有的未来教室}

传统的教学方式已经不适应现代化教学的需要, 智慧 教室应运而生, 它作为一种新型的教育形式和现代化教学 手段, 给教育行业带来了新的变革和机遇。

有别于传统教室, 未来教室主要由以下特征:

\section{1. 智能化的学习空间}

未来教室是学习的智能化空间, 它是集教学环境、教 学内容与活动、教学流程与策略等方面的智慧化于一体智 能化空间。是现代教育从工业社会的 1.0 迈向信息社会的 $2.0[9]$ 的必然产物, 是移动互联网、云计算, 大数据, 人 工智能, 增强现实和虚拟现实等技术的组合。

这些新兴的技术为教育行业带来了全新的变革。集电 子白板功能和触控投影、音响、拾音器等功能为一体的教 学系统, 可以实现无尘教学、保护师生健康, 而且能带来 更好的互动体验, 营造身临其境课堂氛围, 极大程度的激 起学生们的好奇心和学习兴趣; 视频监控系统由WiFi无线 摄像头和配套监控软件构成, 不仅可以帮助监测资产出入、 人员出入, 搭载人脸识别和微表情识别等技术还可以帮助 老师监测在座学生上课情况一一注意力是否集中、对知识 点接受与否等, 将学生课上行为数据化, 实现学习过程中 的多维度监测及评价, 为教师根据教学生情况调整上课内 容提供依据; 还有其他辅助系统, 比如灯光控制系统、人 员考勤系统、空调控制系统、通风换气系统、门窗管理系 统等, 为师生们提供更便利、智能、安全的学习空间。

\section{2. 未来教室中的教与学}

依托于现有的未来教室模型, 国内外对探索新的教学 模式、创新课堂教学方法进行了很多探索和尝试。在这一 教学模式下, 教与学不仅仅局限于课上环节, 而是从课上 到课下、从老师到学生、多方位、多模态的新教学模式。

\section{未来教室教学模式}

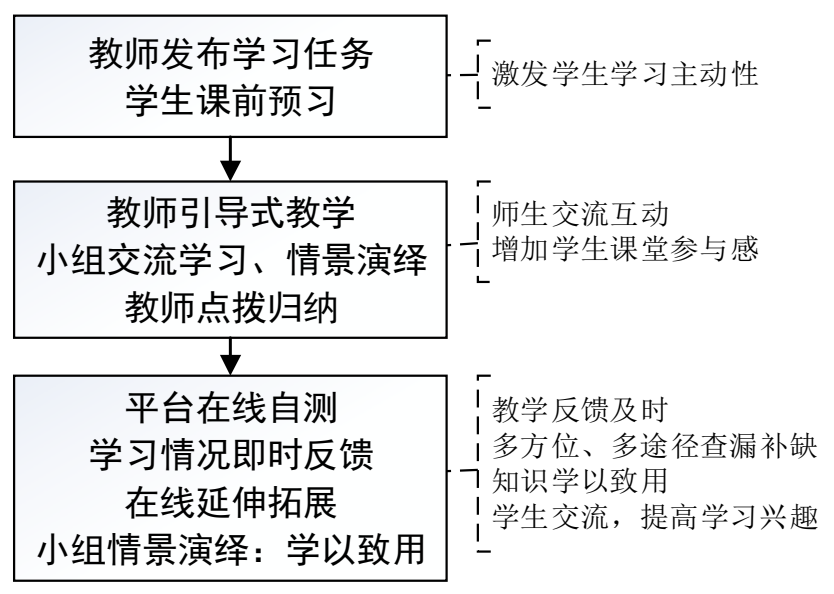

图2 未来教室课堂教学模式。

智慧课堂贯彻落实以学生为中心, 让学生“先学后教”, 其核心是冲分调动学习的积极性, 把学习的权力交给学生, 凸显学生在学习过程当中的主导地位[10]。 
课前鼓励学生积极预习、参与备课; 课中发挥教师积 极引导作用, 鼓励学生以学习小组的形式互相交流学习, 增加学生在课堂活动中的参与程度, 活跃上课气氛, 调动 学生学习兴趣和积极性; 课后组织学生参与平台在线监测、 实现学习情况的即时反馈和查漏补缺, 并且发挥教育云平 台的强大功能, 实现在线延伸扩展, 将所学知识学以致用。

\section{3. 软硬件投入及教学环境构建}

未来的课堂由两部分组成: 硬件设备和软件资源。 其中最主要的部分包括校园局域网建设, 电子白板、VR 展示等交互式展示设备, 手机、笔记本电脑等手持终端, 以及环境监测及自动控制和摄像、人脸识别系统等。

表2 现有未来教室资金及设备投入情况 1 。

\begin{tabular}{lll}
\hline 未来教室项目 & 平均每间教室投 & 项目进程 \\
\hline 苏州市“未来教室”教育信息化 & 入 (万元) & 南 \\
深圳南山区 & 37.5 & 建设中 \\
苏州市金间实验小学 & 100 & 建设中 \\
华师一附中 & 40 & 建设中 \\
\hline
\end{tabular}

其中，以苏州市“未来教室”教育信息化建设为例[7], 相关硬件设备的投入包含了 49 万张 $\mathrm{E}$ 卡通、2811台设备、 未来教室共计192间，此外，还有骨干教师培训和教师应 用培训等软投入, 总计花费两千万, 平均费用无法计算; 2016年,华师一附中未来教室未来的教室设备投资包括3D 打印机, VR眼镜, 编程机器人, 空气质量测试仪, 电子 辐射测试仪等 [11]; 2014年起, 深圳南山区总计投入 1500 万元启动 40 所学校启动未来教室 [12]; 苏州市金间实验小 学花费 100 万左右建造了“未来教室”, 其中投入包括电子 设备、课桌、装修等[13].....不同的国家和地区所采用的 设备配置、购入来源不同，所以笔者只能根据网上已有资 料来估算建设一间未来教室的平均投入。

（四）优劣势分析

尽管未来教室在教学活动中相较于传统课堂有了极 大的改进, 对教学质量也有着极大的改进。但是未来教室 的普及仍旧存在着困难。

1. 高昂的资金设备等投入是未来普及课堂难度的最 大障碍之一。经过笔者调查，一间“基础”的未来教室的造 价 (配备可移动组合式课桌椅、触摸交互式电子白板、智 能监控设备、手持终端), 平均造价在四十万左右, 是一 间传统教室的几十倍。国内目前教育水平区域间差别较大, 而且绝大多数中小学学校都难以承受如此高昂的造价, 这 是造成未来教室难以普及的最大障碍之一。

2.师生难以适应新型的技术。即使有大量的设备和资 金投入, 也是因为教师和学生不熟练, 并没有真正发挥其 作用和优势, 造成极大的浪费[7]。

3.除此之外, 目前实践的未来教室项目中, 还有软件 资源——包括无线广播系统、教学资源库平台、实时跟踪 系统、人工智能控制系统等投资不足, 课外学习资源不多, 不能满足学生的个性化学习需求。

对课堂教学的改革已经势在必行, 但目前传统课堂已 经无法满足需求, 未来教室却还不成熟, 如何走出一条全 新的协同发展的道路成为教育领域最迫切的需求。

\section{5. 探索未来教室与传统课堂协同发展新模式}

课堂的本质是课堂教学的本质是一种奠基生命的师 生特殊交往, 活动过程中, 师生之间不仅存在教与学的交 往活动, 更多的是生命的涌动与成长 [14]。

探索新的课堂模式也是为了更好地实现教学活动, 所 以, 结合当今现状, 本文提出了未来教室与传统课堂协同 发展新模式: 在有限的资源和技术水平下, 着重关注优势 视角的投入和建设, 将未来教室研究和实践的目标定位在 应对传统教室变革、促进教育教学工作的开展及其质量和 效率的提升上来。

\section{1. 教学资源整合}

传统课堂学习资源比较单一, 这是一个很难回避的问 题。传统课堂的教学资源主要是课本及某些课外刊物, 可 是对很多偏远农村和小县城来说, 一座中小学甚至都不存 在图书馆, 即使有, 也有很多问题, 如单一书籍和过时的 内容。

为了解决学习资源的问题, 图书馆建设是一方面, 另 外一方面, 笔者建议可以把目光投向网络资源。

根据《2018年中国图书出版行业发展现状分析及未来 发展趋势预测》 [15], 数字阅读稳步发展, 普及率提高, 而且相比于纸质图书, 有着更新速度快、价格低廉、重复 利用率高等优势, 而且相关获取渠道投入也更加低廉, 主 要资金投入集中在互联网、阅读终端设备、以及图书购买 版权等。

此外, “中国互联网发展统计报告”[16]显示, 截至2018 年6月30日, 中国互联网用户数达到 80200 万, 互联网普及 率为 $57.7 \%$ 。而且这些基础设施的建设为资源共享创造了 极大地便利[17]。

新的教学资源来源如图3所示:

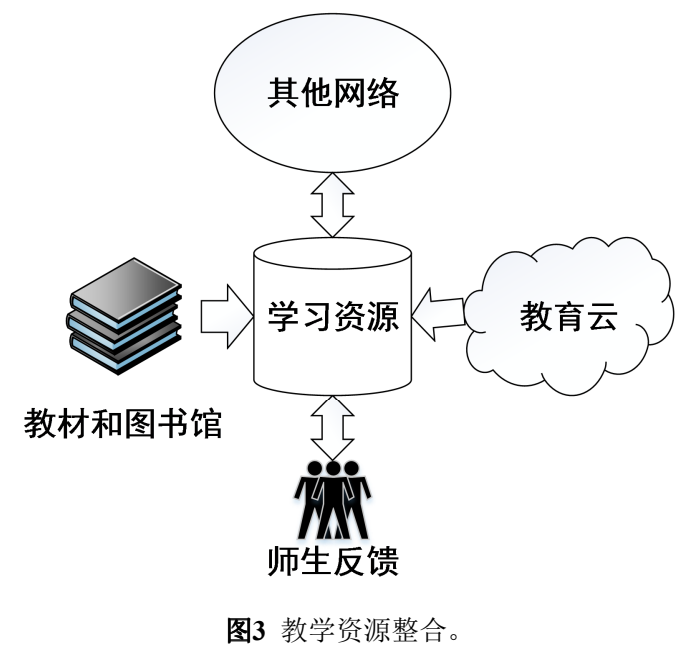

将传统图书馆模式转换成互联网阅读模式, 成为未来 课堂和传统课堂协同发展的第一步。

\section{2. 教学模式设计}

未来的课堂不仅仅是技术的创新, 也是对传统教学模 式的变革和探索。关注学生主体、关注学生综合分析问题、 
解决问题、动手探究、团队合作等学习能力等培养, 而不 再是单纯的填鸭式教学。

以学生为中心, 让学生“先学后教”, 其核心是冲分调 动学习的积极性, 把学习的权力交给学生, 凸显学生在学 习过程当中的主导地位[10]。

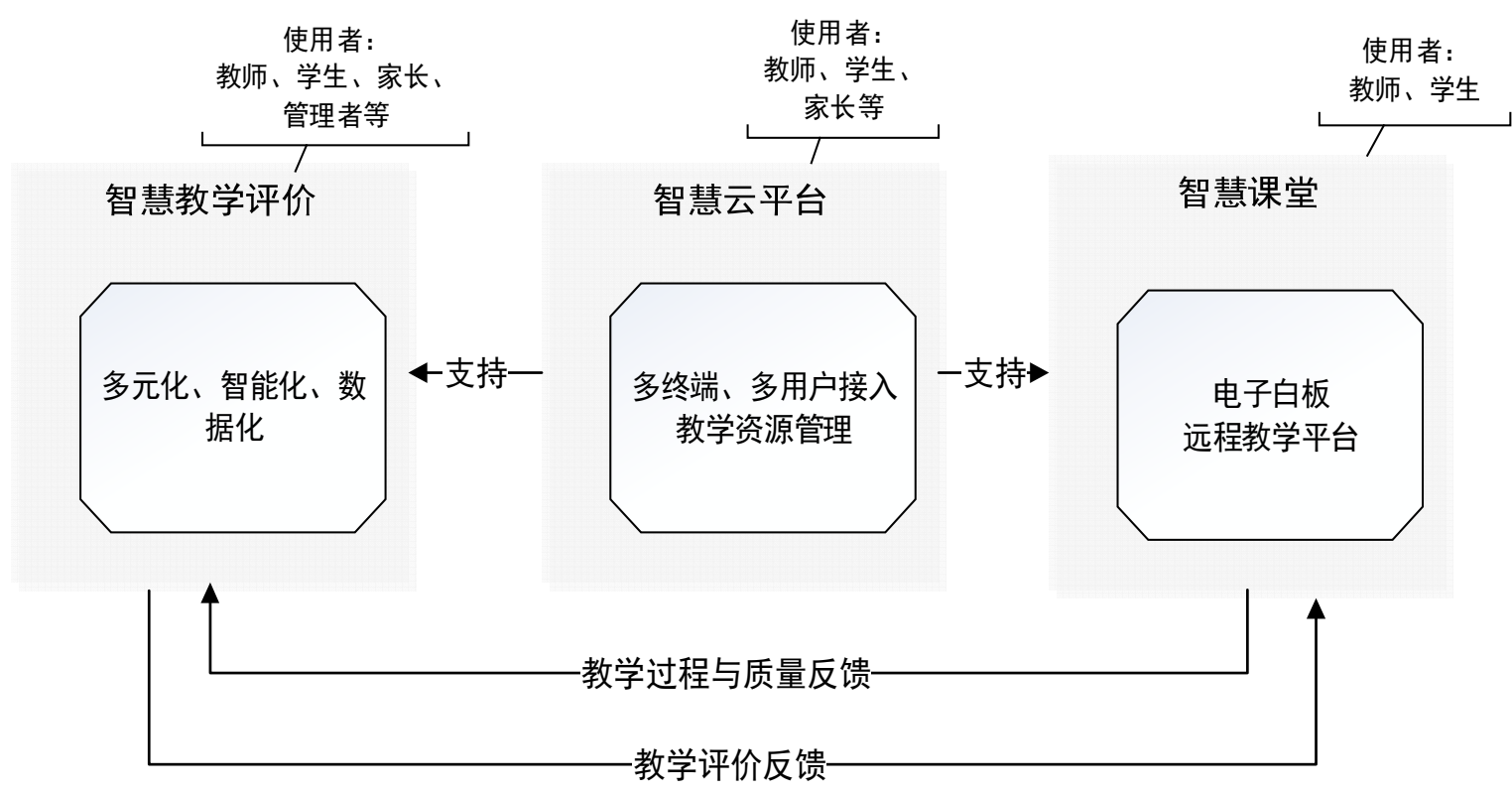

图4 基于优势视角下探索未来教室与传统课堂协同发展新模式。

课前鼓励学生积极预习、参与备课, 激发学习兴趣和 使命感, 让学生不再觉得备课只是老师一个人的任务。

课中发挥教师积极引导作用, 贯彻落实课堂教学改革, 组织小组讨论式课堂, 让同学们在课堂上开放思维、畅所 欲言, 从而发现问题、解决问题、学习知识。并且鼓励学 生以学习小组的形式设计参与情景剧, 增加学生在课堂活 动中的参与程度, 活跃上课气氛。

课后组织学生参与平台在线监测、实现学习情况的即 时反馈和查漏补缺, 并且发挥教育云平台的强大功能, 实 现在线延伸扩展, 将所学知识学以致用。

除此之外, 本文还建议将课堂转移到“教室之外”, 知 识不仅仅存在于书本, 它存在在我们生活的方方面面, 昼 夜交替、气温升降、花草树木、衣食住行。2018年暑假期 间, 笔者曾去澳大利亚进行短期访学。在访学途中发现澳 洲的植物园、动物园等地方经常设有许多的志愿科学讲解 点, 有许多的学校或者家长们带着孩子来游玩, 去面对面 的见识各种植物动物, 听志愿者们讲解环保和小动物们的 关系。这种教学方式, 对学生们来说显然更加生动有趣, 也更加记忆深刻。

这种教学活动, 也让笔者耳目一新, 活泼好奇是学生 们的天性, 与其将学生们整天压抑在四四方方的教室内, 倒不如出去走走, 释放学生们的天性, 同时寓教于乐。

\section{3. 必要的硬件设备}

无论是电子白板、VR眼镜、还是投影仪、摄像等, 所有的硬件设备都是为了创造更加智能、交互体验更加流
以此为基础, 针对教学活动中的各个环节, 本文提出 如图4所示教学流程与基本模式。 
来教室与传统课堂的协同发展的这一新模式, 提高教学质 量, 培养适应现代化发展需求的人才。

课堂的本质是进行教学活动的场所, 未来教室作为技 术与教育融合的产物, 更应关注的是如何更好地服务于教 学活动。学校和教师应立足传统课堂, 选择性的、逐步将 新型的教育理念和技术进行引入和渗透, 从而实现传统课 堂导未来教室的平稳过渡。

\section{参考文献}

[1] 中华人民共和国大事记(上)[J]. 世纪行,2009(10):41-48。

[2] 中华人民共和国大事记(下)[J]. 世纪行,2009(12):39-43。

[3] 吴海燕.用“现实的骨感”吤问传统与未来——传统课堂与未 来课堂在英语学习中的博弯 $[\mathrm{J}]$. 读与写 (教育教学 刊),2016,13(08):132。

[4] 沈霄朦.传统课堂到未来教室转变过程中师生角色的转变 [J].好家长,2015(51):95。

[5] 于冬民.交互式白板——跨越传统课堂和未来教室的桥梁 [J].中国信息技术教育,2008(10):95-96。

[6] 张如玉.生物教学如何实现从传统教室到未来教室的转变 [J].新校园(中旬),2015(11):58.

[7] 刘婷婷,陈增照,刘三(女牙),何秀玲. 创新信息技术 支撑教 学变革 以苏州市“未来教室”教育信息化建设为例 $[\mathrm{J}]$. 中国教育信息化,2016(18):12-15。

[8] 教育部关于印发《教育信息化 2.0 行动计划》的通知 $[\mathrm{J}]$. 中 华人民共和国教育部公报,2018(04):118-125。
[9] 立足智慧课堂 改变教与学方式——访东莞市石龙第三中 学黄小勇[J].教育信息技术,2018(09):16-18+13。

[10] 潘勇. 信息化背景下高中智慧教室建设与实践探索—— 以 华中师大一附中为例 $[\mathrm{J}]$. 软件导刊 (教育技 术),2018,17(06):82-83。

[11] 袁磊. 打造具有东方硅谷气质的未来学校——深圳市南山 区开展未来学校建设的实践探索 [J]. 教育信息技 术,2017(03):22-24。

[12] 智慧地教与学——苏州市金间实验小学“智慧校园”建设情 况[J]. 华夏教师,2017(02):97。

[13] 邱艺,谢幼如,李世杰,黎佳.走向智慧时代的课堂变革 [J].电 化教育研究,2018,39(07):70-76。

[14] 中国互联网络信息中心，李静. 第41次《中国互联网络发展 状况统计报告》发布 [J]. 中国广播, 2018(3):96-96。

[15] 吴鸣晓. “互联网+”时代:中国图书物流建设现状与发展趋 势分析[J]. 经济研究导刊, 2018(7):40-41。

\section{作者简介}

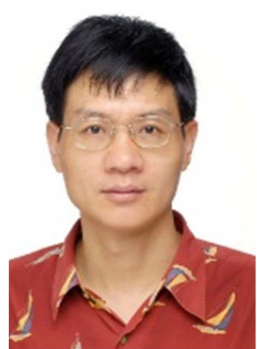

余新国, 男, 华中师范大学国家数字化 学习工程技术研究中心, 副主任、教授、 楚天学者、博士导师, 兼任华师伍伦贡 联合研究院院长。长期以来从事教育机 器人、计算机视觉、自动解答, 其研究 成果获得国内外专家的广泛引用。 